\title{
Report of an extra-pair copulation in the Rufous Hornero, Furnarius rufus (Aves: Furnariidae)
}

\author{
Pedro Diniz ${ }^{1,2,3}$ \& Carlos Biagolini-Jr. ${ }^{1,2,4}$ \\ 1 Universidade de Brasília (UNB), Instituto de Ciências Biológicas (ICB), Departamento de Zoologia, \\ Laboratório de Comportamento Animal. Brasília, DF, Brasil. \\ 2 Universidade de Braślia (UNB), Instituto de Ciências Biológicas (ICB), Departamento de Ecologia, \\ Programa de Pós-Graduação em Ecologia. Brasília, DF, Brasil. \\ ${ }^{3}$ ORCID: http://orcid.org/0000-0002-3193-6376. E-mail: pdadiniz@gmail.com (corresponding author) \\ ${ }^{4}$ ORCID: http://orcid.org/0000-0002-3699-3337. E-mail: c.biagolini@gmail.com
}

\begin{abstract}
In the last decade, studies in bird breeding biology have shown that infidelity is prevalent in socially monogamous species. Here, we describe an extra-pair copulation (EPC) event in the Rufous Hornero (Furnarius rufus), a socially monogamous bird with year-round territoriality and low levels of extra-pair paternity. Before the EPC, a within-pair copulation (WPC) occurred inside the pair's territory. The WPC occurred on the ground and between a banded male (ca. 6 years-old) and an unbanded female. Ten minutes later this breeding pair invaded a neighboring territory, presumably to forage. The territorial male was chased back to its territory by an unbanded male neighbor after being detected. The male neighbor was paired with an unbanded female that did not participate in the aggressive interaction. When flying back to its territory the male neighbor copulated with the territorial female on the ground (ie. EPC). The territorial male flew, vocalized, and perched above the male neighbor, interrupting the EPC. The aggressive interaction then ceased as each pair resumed foraging in their respective territories. These observations suggest that Rufous Horneros can use EPC to obtain immediate benefits (food access in a neighbor's territory). Moreover, WPC may be detected by neighbors and physical mate guarding and/or frequent WPC may be necessary to prevent EPC in the Rufous Hornero.
\end{abstract}

Keywords. Infidelity; Social monogamy; Mate guarding; Eavesdropping.

\section{INTRODUCTION}

The study of copulatory behavior and fertilization patterns contributes towards understanding the evolution of mating systems (Griffith et al., 2002; Brouwer \& Griffith, 2019). In socially monogamous species, extra-pair copulation (EPC) occurs when an individual copulates with another individual outside the pair bond, which may or may not result in extra-pair fertilization (EPF) and the production of extra-pair offspring (Kempenaers \& Schlicht, 2010). Extra-pair paternity (EPP) has been detected in $76 \%$ of the socially monogamous bird species studied to date (Brouwer \& Griffith, 2019). In contrast, little is known about EPC. The lack of data concerning copulatory behavior is due to the difficulty of observing copulations in the field, as they are usually short and cryptic in birds (review in Gill et al., 2020).

Mating strategies are influenced by the context in which EPC occurs. For example, vegetation density reduces an individual's ability to follow mates during daily activities (Mays \& Ritchison, 2004) leading to low mate-guarding efficiency (Sherman \& Morton, 1988; Westneat \& Sherman, 1997; Westneat \& Stewart, 2003). Thus, it is predicted that high levels of monogamy should occur in birds that occupy open habitats (Mee et al., 2004; Muck et al., 2009; Biagolini-Jr. et al., 2017) and when social mates are close (OsorioBeristain \& Drummond, 1998). From the female's perspective, when birds occupy open habitats, EPC should only occur when the territorial male is away from the territory because cues of infidelity can lead to reduced male paternal care of a forthcoming brood (Ewen \& Armstrong, 2000; Harts et al., 2016). Moreover, females may be less willing to engage in EPC due to the high risk of retaliation (e.g., reduced care or aggressions) by their social mates (Valera et al., 2003; Westneat \& Stewart, 2003).

The Rufous Hornero, Furnarius rufus (Passeriformes, Furnariidae) is a medium-sized passerine $(16-23 \mathrm{~cm} ; 31-65 \mathrm{~g})$, commonly found 
in second-growth scrub, pastureland, and urban areas in southern South America (Remsen-Jr. \& Bonan, 2020). The Rufous Hornero is a socially monogamous, duetting species with typically slow pace of life-history: year-round territoriality, long-term pair bonding, and high nesting success (Fraga, 1980; Diniz et al., 2018). A previous study that applied molecular tools to assess the occurrence of extra-pair paternity shows that EPP levels are low in this species (3.33\% of 120 offspring and $6.52 \%$ of 46 broods) and that one extra-pair nestling was sired by a male neighbor (Diniz et al., 2019). Field observations and images from citizen scientists suggest that females produce a copulation solicitation call (Fraga, 1980) and that copulations occur conspicuously on the ground (Paula, 2014) or cryptically inside the nest (Freitas, 2013) or on dense trees (Figueiredo, 2011) in the Rufous Hornero. Here, we describe an event of EPC that suggests that the low EPP recorded for Rufous Horneros could be explained by the constraints of females to perform EPC when they are close to their partners.

\section{MATERIAL AND METHODS}

We observed an event of EPC performed after a within-pair copulation (WPC) had occurred in the juncture of two territories, each defended by different Rufous Hornero mated pairs. The records were made during a one-day fieldwork to resight a few banded pairs in the Universidade de Brasília campus, Brasília, central Brazil ( $\left.15^{\circ} 46^{\prime} 13.36^{\prime \prime} \mathrm{S} ; 47^{\circ} 52^{\prime} 12.21^{\prime \prime} \mathrm{W}\right)$, at $16: 43 \mathrm{~h}$ on 20 September 2020. This period is considered the beginning of the breeding season in the studied population when most females are probably fertile (Diniz et al., 2018). Individuals of this population were marked, from 2013 to 2015, with unique combinations of plastic color bands and/or one numbered aluminum band supplied by the Brazilian Bird Banding Agency (CEMAVE/ICMBio) (see tag protocol description in: Diniz et al., 2016). A previous study in this population did not record any EPC despite the big sampling effort (101 hours of observations on 12 breeding pairs; Diniz et al., 2019).

The pairing and territorial statuses of each pair were assigned by observing partners duetting and foraging closer to each other for approximately 20 minutes before and after the copulation records. One of the mated pairs was composed by a banded male ( $\geq 6$ years-old) and an unbanded female ("Territorial Pair", hereafter). This male was observed on previous duetting studies conducted up to 2015, when it was still mated with a banded female and had its territory perimeter estimated (Diniz et al., 2018, 2019). Thus, the female of the Territorial Pair was replaced at least once in the last six years. The second mated pair was located in an adjacent territory and was composed of unbanded individuals that had not been studied previously ("Neighbor Pair", hereafter). Distances between birds and between birds and territories' borders were estimated visually by the observer (PD).

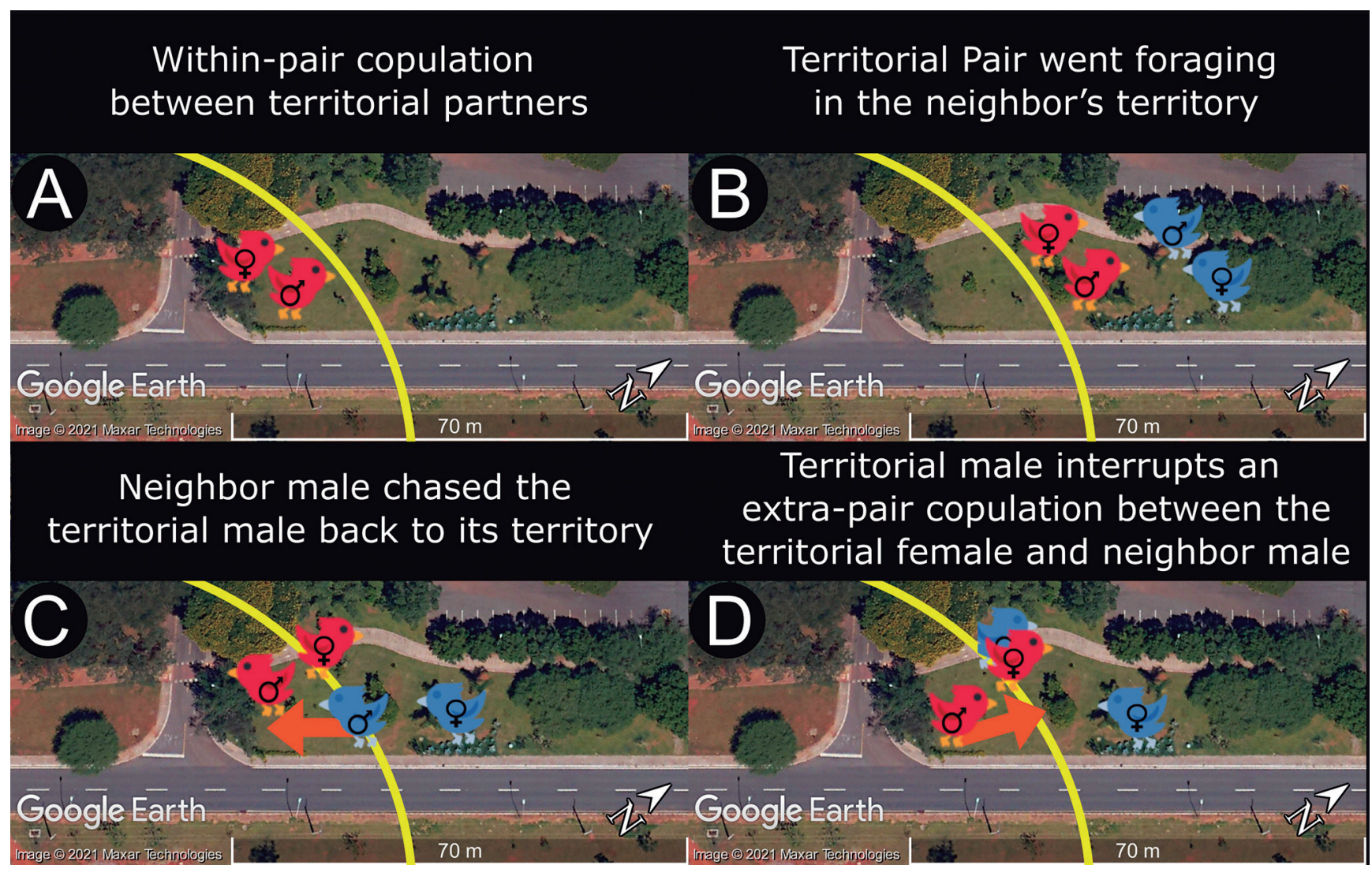

Figure 1. Chronology of records of within-pair and extra-pair copulations involving two pairs of Rufous Horneros that inhabited adjacent territories. (A) WPC between members of the Territorial Pair; (B) Territorial Pair foraging outside its territory; (C) The male neighbor chases the territorial male away from its territory; (D) The male neighbor copulates with the territorial female (i.e., EPC). The yellow line indicates the border separating the Territorial Pair (red) and the Neighbor Pair (blue). Image source: Google Earth. 


\section{RESULTS}

The WPC occurred between the members of the Territorial Pair (Fig. 1A). Both individuals were foraging on the lawn in an open spot surrounded by trees and located between a sidewalk and a road (Fig. 1). The partners were close to each other $(<5 \mathrm{~m})$ and close to the territorial border. The pair copulated for $\sim 5 \mathrm{~s}$ and resumed foraging. Ten minutes later the Territorial Pair was foraging outside its territory (distance between partners: $5 \mathrm{~m}$ ) and probably inside the Neighbor Pair's territory (distance from the border, male: $11 \mathrm{~m}$, female: $6 \mathrm{~m}$; Fig. 1B). The male neighbor vocalized and chased the territorial male for $30 \mathrm{~m}$ back to the territorial male territory, where both perched on the ground approximately $14 \mathrm{~m}$ from the territorial border (Fig. 1C). The territorial female followed both males during the chase and returned to its territory, but perched earlier, on the ground, closer $(5 \mathrm{~m})$ to the territorial border (distance to the males: $11 \mathrm{~m}$ ). The female neighbor also followed the males but perched inside its territory (distance to the border: $6 \mathrm{~m}$; perch heigh: $\sim 2 \mathrm{~m}$ ).

The EPC occurred between the territorial female and male neighbor inside the territory of Territorial Pair. After chasing the territorial male back to its territory, the male neighbor flew toward its territory, and perched nearby the territorial female on the ground (Fig. 1D). The territorial female did not produce copulation solicitation calls and did not show any aggressiveness towards the male neighbor. During the EPC, the territorial male flew, vocalized, and perched above the male neighbor, presumably to interrupt the copulation, which lasted for $\sim 4 \mathrm{~s}$. The male neighbor flew in the direction of its territory and perched closer to the territorial border and the female neighbor. Finally, both pairs resumed foraging and moved further apart within their respective territories.

\section{DISCUSSION}

The observation that Rufous Hornero performed WPC before an extra-territorial foray, followed by an EPC when the social male was physically distant, brings to light new interpretations concerning elements that may limit or promote EPP in this species. First, the territorial female was not aggressively assailed by the extra-pair male, suggesting that cases of EPP in Rufous Horneros should not be interpreted as forced copulation (Bukacińska et al., 1998; Gill et al., 2020). Moreover, as it is clear that the within-pair male was alive, low levels of EPP could not be explained by possibilities of establishment of a new pair bond after a previous partner dies (Petrie \& Kempenaers, 1998) or divorces (Culina et al., 2015; Boucherie et al., 2018).

Our observations indicate that mate guarding behavior is the key component that determines the low rates of EPP in the Rufous Hornero. However, our observations indicate that mate guarding efficiency is reduced when males engage in costly territorial disputes since males cannot guard their mates and fight with a neigh- bor at the same time (Meek \& Robertson, 1994; Low 2006). Physical mate-guarding behavior is described as behavioral adaptations used to prevent EPP (Schamel et al., 2004), commonly expressed through two general components: (i) increased copulation frequency; (ii) following female during the fertile period, which can be an attempt to prevent females from extra-territorial forays or to dissuade other males from approaching (Westneat \& Stewart, 2003).

Because the Rufous Hornero is a highly altricial species (Dial, 2003) with a great demand for parental care (Massoni et al., 2012), the use of social behavior to prevent EPP is determinant for male fitness (Gilbert et al., 1998; Valera et al., 2003; Hoi et al., 2013). By tracking the female during the breeding season and a possible reduction of parental effort in face of infidelity cues (Westneat et al., 2013; Reding, 2015; Ball et al., 2017), males might increase the cost of EPC to females, which could contribute to low levels of EPP in this species (Ewen \& Armstrong, 2000; Matysioková \& Remeš, 2013; Harts et al., 2016). In contrast to physical mate guarding (Valera et al., 2003), a previous study with Rufous Horneros showed that male duet responsiveness was not associated with the female fertile period, suggesting that males do not acoustically guard paternity (Diniz et al., 2018).

It is known that birds, in general, copulate more times than necessary for fertilization, which suggests that females obtain benefits by exploiting male interest in within and extra-pair copulations. These benefits can be immediate (e.g., food access in males' territories) or future (e.g., paternal care) (Velando, 2004). The observation that the Rufous Hornero Territorial Pair performed a WPC before an extra-territorial foray indicates that increased copulation frequency may be a mate guarding strategy. On the other hand, the EPC after the female's entry into the neighbor's territory could be associated with gaining access to resources in that territory. Females can seek EPC for other reasons (reviewed in Brouwer \& Griffith, 2019), such as to ensure fertility when mated to an infertile male (Sheldon, 1994). Concerning the possibility of males chasing their social mate to prevent EPC, it is known that females are more likely to escape male surveillance when the vegetation is dense (Mays \& Ritchison, 2004). Thus, we expect that mate guarding in urban environments (such as our study site) is facilitated because this habitat typically presents low vegetation cover (Samia et al., 2015).

We recommend that future studies evaluate the effects of short-term removal of pair males during the female fertile period on female behavior, territorial intrusion, and EPC in the Rufous Hornero (Dowling \& Webster, 2018). Then, we could get insight into the role of female infidelity and mate-guarding in the occurrence of EPC in this species (Hall \& Peters, 2009). Unfaithful females are expected to engage in off-territorial forays and singing more solos to attract extra-pair males in the absence of its mate; also, the lack of mate-guarding may increase extra-pair male intrusions and EPCs (Brylawski \& Whittingham, 2004; Johnsen et al., 2008; Hall \& Peters, 2009; Dowling \& Webster, 2018). 


\section{ACKNOWLEDGMENTS}

This work was supported by Coordenação de Aperfeiçoamento de Pessoal de Nível Superior - Brasil (CAPES) (Postdoctoral scholarship to P. Diniz under grant number 88887.469218/2019-00). We thank Regina H. Macedo and one Anonymous Reviewer for their suggestions and comments on the manuscript.

\section{AUTHORS' CONTRIBUTIONS}

Pedro Diniz: Conceptualization, Investigation, Methodology, Writing - original draft, Writing - review \& editing. Carlos Biagolini-Jr.: Writing - original draft, Writing - review \& editing. Both authors read and approved the final manuscript.

\section{CONFLICT OF INTEREST}

Authors declare there are no conflicts of interest. REFERENCES

Ball, A.D.; van Dijk, R.E.; Lloyd, P.; Pogány, Á.; Dawson, D.A.; Dorus, S.; Bowie, R.C.K.K.; Burke, T. \& Székely, T. 2017. Levels of extra-pair paternity are associated with parental care in penduline tits (Remizidae). Ibis, 159(2): 449-455. DOI

Biagolini-Jr., C.; Westneat, D.F. \& Francisco, M.R. 2017. Does habitat structural complexity influence the frequency of extra-pair paternity in birds? Behavioral Ecology and Sociobiology, 71(7): 101. DOI

Boucherie, P...; Poulin, N. \& Dufour, V. 2018. Not much ado about something: behavioural mechanisms of pair bond separation and formation in longterm pairing rooks. Écoscience, 25: 71-83. D0I

Brouwer, L. \& Griffith, S.C. 2019. Extra-pair paternity in birds. Molecular Ecology, 28(22): 4864-4882. D0I

Brylawski, A.M.Z. \& Whittingham, L.A. 2004. An experimental study of mate guarding and paternity in house wrens. Animal Behaviour, 68(6): 1417-1424. DOI

Bukacińska, M.; Bukaciński, D.; Epplen, J.T.; Sauer, K.P. \& Lubjuhn, T. 1998. Low frequency of extra-pair paternity in Common Gulls (Larus canus) as revealed by DNA fingerprinting. Journal of Ornithology, 139(4): 413-420. DOI

Culina, A.; Radersma, R. \& Sheldon, B.C. 2015. Trading up: The fitness consequences of divorce in monogamous birds. Biolological Reviews, 90(4): 1015-1034. DOI

Dial, K.P. 2003. Evolution of avian locomotion: correlates of flight style, locomotor modules, nesting biology, body size, development, and the origin of flapping flight. The Auk, 120(4): 941-952. DOI

Diniz, P.; Macedo, R.H. \& Webster, M.S. 2019. Duetting correlates with territory quality and reproductive success in a suboscine bird with low extra-pair paternity. The Auk, 136: 1-13. D0I

Diniz, P.; Ribeiro, P.H.L; Rech, G.S. \& Macedo, R.H. 2016. Monochromatism, cryptic sexual dimorphism and lack of assortative mating in the Rufous Hornero, Furnarius rufus albogularis. Emu, 116(3): 294-300. DOI

Diniz, P.; Silva-Jr., E.F;; Webster, M.S. \& Macedo, R.H. 2018. Duetting behavior in a Neotropical ovenbird: sexual and seasonal variation and adaptive signaling functions. Journal of Avian Biology, 49(4): jav-01637. DOI

Dowling, J. \& Webster, M.S. 2018. Acoustic and physical mate guarding have different effects on intruder behaviour in a duetting songbird. Animal Behaviour, 135: 69-75. D0I
Ewen, J.G. \& Armstrong, D.P. 2000. Male provisioning is negatively correlated with attempted extrapair copulation frequency in the stitchbird (or hihi). Animal Behaviour, 60(4): 429-433. DOI

Figueiredo, N.S. 2011. Wiki Aves - A Enciclopédia das Aves do Brasil. Available: http://www.wikiaves.com/486091. Access: 06/04/2021.

Fraga, R.M. 1980. The Breeding of Rufous Horneros (Furnarius rufus). The Condor, 82: 58-68. D01

Freitas, J.A. 2013. Wiki Aves - A Enciclopédia das Aves do Brasil. Available: http://www.wikiaves.com/1066264. Access: 06/04/2021.

Gilbert, L.; Burke, T. \& Krupa, A. 1998. No evidence for extra-pair paternity in the western gull. Molecular Ecology, 7(11): 1549-1552. D0I

Gill, L.F.; Van Schaik, J.; Von Bayern, A.M.P. \& Gahr, M.L. 2020. Genetic monogamy despite frequent extrapair copulations in "strictly monogamous" wild jackdaws. Behavioral Ecology, 31(1): 247-260. D01

Griffith, S.C.; Owens, I.P.F \& Thuman, K.A. 2002. Extra pair paternity in birds: a review of interspecific variation and adaptive function. Molecular Ecology, 11(11): 2195-2212. DOI

Hall, M. \& Peters, A. 2009. Do male paternity guards ensure female fidelity in a duetting fairy-wren? Behavioral Ecology, 20(1):222-228. DOI

Harts, A.M.F.; Booksmythe, I. \& Jennions, M.D. 2016. Mate guarding and frequent copulation in birds: A meta-analysis of their relationship to paternity and male phenotype. Evolution, 70(12): 2789-2808. DOI

Hoi, H.; Krištofik, J. \& Darolová, A. 2013. Experimentally simulating paternity uncertainty: immediate and long-term responses of male and female reed warblers Acrocephalus scirpaceus. PLoS One, 8: e62541. DOI

Johnsen, A.; Pärn, H.; Fossøy, F.; Kleven, 0.; Laskemoen, T. \& Lifjeld, J.T. 2008. Is female promiscuity constrained by the presence of her social mate? An experiment with bluethroats Luscinia svecica. Behavioral Ecology and Sociobiology, 62(11): 1761-1767. DOI

Kempenaers, B.\& Schlicht, E. 2010. Extra-pairbehaviour.In:Kappeler, P.Animal Behaviour: Evolution and Mechanisms. Berlin, Springer. p. 359-411.

Low, M. 2006. The energetic cost of mate guarding is correlated with territorial intrusions in the New Zealand stitchbird. Behavioral Ecology, 17(2): 270-276. DOI

Massoni, V.; Reboreda, J.C.; López, G.C. \& Aldatz, M.F. 2012. High coordination and equitable parental effort in the Rufous Hornero. The Condor, 114(3): 564-570. D0I

Matysioková, B. \& Remeš, V. 2013. Faithful females receive more help: The extent of male parental care during incubation in relation to extra-pair paternity in songbirds. Journal of Evolutionary Biology, 26: 155-162. DOI

Mays, H.L. \& Ritchison, G. 2004. The effect of vegetation density on male mate guarding and extra-territorial forays in the yellow-breasted chat (Icteria virens). Naturwissenschaften, 91(4): 195-198. DOI

Mee, A.; Whitfield, D.P.; Thompson, D.B.A. \& Burke, T. 2004. Extrapair paternity in the common sandpiper, Actitis hypoleucos, revealed by DNA fingerprinting. Animal Behaviour, 67(2): 333-342. D01

Meek, S.B. \& Robertson, R.J. 1994. Interspecific competition for nestboxes affects mate guarding in eastern bluebirds, Sialia sialis. Animal Behaviour, 47(2): 295-302. DOI

Muck, C.; Kempenaers, B.; Kuhn, S.; Valcu, M. \& Goymann, W. 2009. Paternity in the classical polyandrous black coucal (Centropus grillii) - a cuckoo accepting cuckoldry? Behavioral Ecology, 20(6): 1185-1193. D01

Osorio-Beristain, M. \& Drummond, H. 1998. Non-aggressive mate guarding by the blue-footed booby: a balance of female and male control. Behavioral Ecology and Sociobiology, 43(4-5): 307-315. DOI

Paula, L.A. 2014. Wiki Aves - A Enciclopédia das Aves do Brasil. Available: http://www.wikiaves.com/3537244. Access: 06/04/2021.

Petrie, M. \& Kempenaers, B. 1998. Extra-pair paternity in birds: explaining variation between species and populations. Trends in Ecology \& Evolution, 13: 52-58. DOI 
Reding, L. 2015. Increased hatching success as a direct benefit of polyandry in birds. Evolution, 69: 264-270. DOI

Remsen-Jr., J.V. \& Bonan, A. 2020. Rufous Hornero (Furnarius rufus), version 1.0. In: del Hoyo, J.; Elliott, A.; Sargatal, J.; Christie, D.A. \& de Juana, E. Birds of the world. Ithaca, Cornell Lab of Ornithology.

Samia, D.S.M.; Nakagawa, S.; Nomura, F.; Rangel, T.F. \& Blumstein, D.T. 2015. Increased tolerance to humans among disturbed wildlife. Nature Communications, 6 (8877): 1-8. D0I

Schamel, D.; Tracy, D.M.; Lank, D.B. \& Westneat, D.F. 2004. Mate guarding, copulation strategies and paternity in the sex-role reversed, socially polyandrous red-necked phalarope Phalaropus lobatus. Behavioral Ecology and Sociobiology, 57(2): 110-118. D01

Sheldon, B.C. 1994. Male phenotype, fertility, and the pursuit of extra-pair copulations by female birds. Proceedings of the Royal Society of London Series B: Biological Sciences, 257: 25-30. D01
Sherman, P.W. \& Morton, M.L. 1988. Extra-pair fertilizations in mountain whitecrowned sparrows. Behavioral Ecology and Sociobiology, 22(6): 413-420. D0|

Valera, F.; Hoi, H. \& Krištín, A. 2003. Male shrikes punish unfaithful females. Behavioral Ecology, 14(3): 403-408. D0I

Velando, A. 2004. Female control in yellow-legged gulls: trading paternity assurance for food. Animal Behaviour, 67(5): 899-907. DOI

Westneat, D.F. \& Sherman, P.W. 1997. Density and extra-pair fertilizations in birds: A comparative analysis. Behavioral Ecology and Sociobiology, 41(4): 205-215. D0I

Westneat, D.F. \& Stewart, I.R.K. 2003. Extra pair paternity in birds: causes, correlates, and conflict. Annual Review of Ecology, Evolution, and Systematics, 34: 365-396. DOI

Westneat, D.F.; Schofield, M.; Wright, J. 2013. Parental behavior exhibits among-individual variance, plasticity, and heterogeneous residual variance. Behavioral Ecology, 24(3): 598-604. D0I 